\title{
STUDI PENGEMBANGAN FASILITAS PELABUHAN PERIKANAN PANTAI SADENG, GIRISUBO, GUNUNG KIDUL
}

\author{
Salim ${ }^{1 *}$,Waris Wibowo ${ }^{1}$, Wegig Pratama ${ }^{1}$ \\ ${ }^{1}$ Sekolah Tinggi Maritim Yogyakarta, \\ Jl. Magelang KM 4.4, Yogyakarta 55284, Indonesia \\ Email: salimtawang@gmail.com
}

\begin{abstract}
Abstrak
Pelabuhan Sadeng merupakan pelabuhan perikanan terbesar di Provinsi Daerah Istimewa Yogyakarta (DIY) yang dimanfaatkan untuk aktivitas bongkar muat dan pelelangan ikan. Aktifitas bongkar muat telah didukung dengan fasilitas yang memadai untuk kategori pelabuhan tipe C. Semakin meningkatnya aktivitas bongkar muat di pelabuhan Sadeng tersebut mendorong untuk meningkatkan fasilitas dari pelabuhan tipe $C$ ke tipe B. Studi kelayakan untuk mengidentifikasi fasilitas dan sarana pendukung lainnya sangat diperlukan dalam rangka untuk memenuhi persyaratan kesesuaian pelabuhan Sadeng sebagai pelabuhan tipe B. Riset ini bertujuan untuk mengetahui kesiapan pelabuhan Sadeng menjadi pelabuhan tipe B terkait dengan fasilitas dan sarana prasarana pendukung yang dipersyaratkan. Metode penelitian ini menggunakan pendekatan deskriftif dengan pengambilan data melalui observasi, interview, dan dokumentasi. Berdasarkan hasil studi menunjukkan bahwa pelabuhan Sadeng telah memenuhi syarat untuk peningkatan tipe dari pelabuhan tipe $C$ ke pelabuhan tipe $B$, terkait dengan kesiapan fasilitas, fungsional, dan fasilitas penunjang.
\end{abstract}

Kata kunci: Pelabuhan, Sadeng, Perikanan

\section{PENDAHULUAN}

Pelabuhan Perikanan Pantai (PPP) Sadeng, terletak diteluk Sadeng pada koordinat 11.00 52' 32" BT dan 80 12'30" LS yang tepatnya didesa Songbanyu Pucung, Kecamatan Girisubo, Kabupaten Gunung Kidul, propinsi Daerah Istimewa Yogyakarta. Pantai Sadeng ini berjarak $46 \mathrm{~km}$ dari arah kota Wonosari dan 80 kilometer dari arah kota Yogyakarta

Pelabuhan Perikanan Pantai Sadeng saat ini termasuk ke dalam pelabuhan tipe C, (Permen. 16/MEN/2006). Dengan meningkatnya aktifitas kapal perikanan saat ini, fasilitas pelabuhan perikanan Sadeng perlu kiranya lebih dioptimalkan perannya untuk melayani kegiatan kapal yang beroperasi di pelabuhan Sadeng. Peningkatan meliputi penambahan armada kapal baik dari segi ukuran GT (gross tonnage) dan jumlah kapalnya. Untuk mewadahi peningkatan ini, maka klasifikasi PPP Sadeng dapat ditingkatkan ke Pelabuhan Perikanan tipe B tinggal memperluas kolam pelabuhan sesuai tipenya. Karena fasilitas yang lain sudah memenuhi. Pengoptimalan ini dapat dikaji dari ketersediaan dan kelayakan fasilitas pokok, fungsional serta penunjang di pelabuhan Sadeng.

Identifikasi mengenai pengoptimalan fasilitas pelabuhan perikanan Sadeng diperlukan untuk mendapat gambaran tentang kondisi dan kualitas layanan pelabuhan sehingga dapat digunakan untuk membuat rekomendasi tentang pengembangan pelabuhan perikanan Sadeng.

\section{LANDASAN TEORI \\ Pengertian Pelabuhan Perikanan}

Berdasarkan Peraturan Menteri

Kelautan dan Perikanan nomer 16 tahun 2006, menyatakan bahwa pelabuhan perikanan adalah tempat yang terdiri atas daratan dan perairan di sekitarnya dengan batas - batas tertentu sebagai tempat kegiatan pemerintahan dan kegiatan sistem bisnis perikanan yang digunakan sebagai tempat kapal perikanan bersandar, berlabuh atau bongkar muat yang dilengkapi dengan fasilitas keselamatan pelayaran dan kegiatan penunjang perikanan.

Menurut Yuspardianto (2006), bahwa pelabuhan perikanan merupakan prasarana yang mendukung untuk meningkatkan 
pendapatan nelayan juga sekaligus perikanan, kepabeanan, keimigrasian, serta mendorong nilai investasi dibidang pengendalian lingkungan.

perikanan.

Menurut Suryana (2008) menyatakan bahwa pelabuhan merupakan pusat aktifitas ekonomi kelautan, sehingga keberadaanya sangat diperlukan. Keberadaan pelabuhan perikanan sangat penting untuk menunjang aktifitas penangkapan dalam kegiatan pemanfaatan dan pengelolaan sumberdaya perikanan mulai dari kegiatan praproduksi, produksi, sampai pada pasca produksi. Pelabuhan perikanan juga memberikan kontribusi untuk meningkatkan produksi ikan, pemasukan devisa, membuka lapangan kerja, peningkatan pendapatan, peningkatan penyediaan ikan segar dan peningkatan pendapatan pemerintah lokal. Selain itu, pelabuhan juga mempunyai peranan penting yang terletak pada fasilitasnya sebagai penunjang dalam kegiatan operasi yang optimal (Arsyad, 2014).

\section{Fungsi Pelabuhan Perikanan}

Menurut Peraturan Menteri Kelautan Dan Perikanan Nomor 8/MEN/2012, Tentang Kepelabuhan Perikanan, (2012), fungsi Kepelabuhan Perikanan adalah : (1).Fungsi pendukung kegiatan pengelolaan dan pemanfaatan sumberdaya ikan dan lingkunganya mulai dari praproduksi, produksi, pengolahan, dan pemasaran, (2). Fungsi pengusahaan yang meliputi pelayanan labuh dan tambat, bongkar muat ikan, pengolahan hasil perikanan, pemasaran dan distribusi ikan, pemanfaatan fasilitas dan lahan di pelabuhan perikanan, perbaikan dan pemeliharaan, logistik dan perbekalan kapal perikanan, tempat wisata bahari, serta pelayanan jasa lain sesuai perundang - undangan, dan (3). Fungsi pemerintahan meliputi pelayanan pembinaan mutu dan pengolahan hasil, pengumpulan data tangkapan, tempat penyuluhan dan pengembangan masyarakat nelayan, pelaksanaan pengawasan dan pengendalian, kesyahbandaran, karantina, publikasi sandar dan labuh serta pengawasan, hasil penelitian kelautan dan

\section{Klasifikasi Pelabuhan Perikanan}

Berdasarkan Surat Keputusan Menteri Kelautan Dan Perikanan No.: Kep.10/MEN/2004, Tentang Pelabuhan Perikanan Jakarta, Departemen Kelautan Dan Perikanan Dinas Kelautan Dan Perikanan Propinsi Daerah Istimewa Yogyakarta, (2004) diklasifikasikan menjadi 4 klas : (1) Pelabuhan Perikanan Klas A atau (Pelabuhan Perikanan Samudera disingkat PPS), (2) Pelabuhan Perikanan Klas B (Pelabuhan Perikanan Nusantara disingkat PPN), (3) Pelabuhan Perikanan Klas C (Pelabuhan Perikanan Pantai disingkat PPP), (4) Pelabuhan Perikanan Klas D (Pelabuhan Pendaratan Ikan disingkat PPI

\section{Fasilitas Pelabuhan Perikanan}

Menurut Peraturan Menteri Kelautan Dan Perikanan Nomor 8/MEN/2012, Tentang Kepelabuhan Perikanan, (2012), dalam rangka menunjang fungsi pelabuhan perikanan, setiap pelabuhan perikanan memiliki fasilitas pokok, fasilitas fungsional dan fasilitas penunjang yang meliputi: (1) Fasilitas pokok atau disebut fasilitas dasar diperlukan untuk menunjang aktifitas di pelabuhan. Fasilitas pokok ada yang berfungsi sebagai penjamin keamanan dan kelancaran kapal baik ketika berlayar maupun masuk ke pelabuhan, saat berlabuh maupun bertambat, (2) Fasilitas fungsional yang berfungsi untuk menunjang kegiatan fasilitas pokok, sehingga dapat meningkatkan nilai guna suatu aktifitas, (3) Fasilitas penunjang merupakan fasilitas yang secara tidak langsung dapat menunjang fungsi fasilitas lainnya.

Lebih lanjut dalam Peraturan Menteri

Kelautan Dan Perikanan Nomor 8/MEN/2012, Tentang Kepelabuhan Perikanan, (2012) bahwa fasilitas yang wajib minimal pada pelabuhan perikanan meliputi: (1) Fasilitas pokok terdiri dari lahan, dermaga, kolam pelabuhan, jalan komplek dan drainase, (2) Fasilitas fungsional terdiri dari kantor administrasi 
pelabuhan, TPI, suplai air bersih dan instalasi listrik, dan (3) Fasilitas penunjang terdiri dari pos jaga dan MCK.

\section{METODE}

Pelaksanaan penelitian dilaksanakan di Pantai Sadeng, Girisubo, Kab. Gunungkidul dengan metode deskripsi bersifat studi kasus dengan melakukan survey (wawancara, observasi dan dokumentasi) mengenai fasilitas yang berada di Pelabuhan Perikanan Pantai Sadeng. Fasilitas ini meliputi Fasilitas Pokok, Fasilitas Fungsional, Fasilitas Penunjang

\section{HASIL DAN PEMBAHASAN Fasilitas Pokok}

Fasilitas pokok yang berfungsi untuk melindungi kegiatan umum di pelabuhan perikanan dari segenap gangguan alam seperti gelombang, arus, angin, pengendapan lumpur/pasir dan sebagainya di PPP Sadeng meliputi :

\section{Fasilitas Lahan Pelabuhan) \\ (Tanah/Lahan}

Tanah atau lahan merupakan syarat utama untuk keberadaan suatu pelabuhan perikanan. Luas atau lahan dapat ditentukan dari tipe pelabuhan perikanan. Luas lahan yang tersedia di Pelabuhan Sadeng sekitar 5 ha. Berdasarkan Kriteria Teknis (Tersier) (Pelabuhan Perikanan Wahana Penyaluran Investasi Usaha Departemen Pertanian, 1994) (Dirjen Perikanan, 1994) luas lahan yang dibutuhkan sekitar 5 ha. Berarti untuk lahan di Pelabuhan Perikanan Pantai Sadeng sudah memenuhi syarat teknis. Lahan di Pelabuhan Perikanan Pantai Sadeng sebenarnya masih dapat diperluas kearah utara yang masih tersedia relative luas.

\section{Fasilitas Tambat (Dermaga/Jetty)}

Dermaga Pelabuhan Perikanan Pantai Sadeng memiliki panjang $485 \mathrm{~m}$. Dermaga berfungsi sebagai tempat bersandarnya kapal - kapal untuk melakukan pembongkaran ikan dan pengisian bahan serta perbekalan bagi kapal - kapal yang akan melakukan penangkapan ikan ke laut. Dermaga di Pelabuhan Perikanan Pantai Sadeng dibagi menjadi 2 yang diperuntukan bagi kapal - kapal ukuran di bawah 5 GT. Sedangkan untuk kapal - kapal yang berukuran di atas 5 GT bersandar di dermaga yang lebih panjang dan dalam.

\section{Fasilitas Perairan (Kolam, alur} Pelabuhan) Alur Pelayaran/Pelabuhan : Panjang alur pelayaran di Pelabuhan Perikanan Pantai Sadeng sekitar $200 \mathrm{~m}$ dan lebar $25 \mathrm{~m}$ serta kedalaman 5-7 m. Alur ini berfungsi untuk memberi jalan pada lalu lintas kapal yang akan keluar masuk wilayah pelabuhan dengan aman serta mudah bagi kapal - kapal ikan agar tidak mengalami kecelakaan. Manfaat lain dari alur pelabuhan adalah untuk menghilangkan kesulitan yang akan timbul karena gerakan kapal dan gangguan alam.

\section{1) Kolam Pelabuhan/Tempat Labuh kapal}

Tempat labuh kapal dibagi menjadi 2 bagian; dimana bagi kapal - kapal yang berukuran di bawah 5 GT ditempatkan pada posisi sebelah utara yang mana kedalaman perairan relative lebih dangkal. Luas labuh untuk kapal dibawah 5 GT seluas $5.700 \mathrm{~m}^{2}$. Sedangkan untuk kapal - kapal yang berukuran diatas 5 GT berada di daerah yang lebih tengah (dalam). Luas labuh untuk kapal ikan yang berukuran di atas 5 GT sekitar $22.900 \mathrm{~m}^{2}$.

\section{Fasilitas Pelindung (Breakwater, Groin dan Revertment)}

Pada Pelabuhan Perikanan Pantai Sadeng, sudah ada fasilitas break water atau penahan gelombang dengan panjang $135 \mathrm{~m}$ dan di sisakan untuk alur pelayaran sekitar $25 \mathrm{~m}$. Untuk groin/penahan pasir di taruh di depan break water yang berfungsi untuk melindungi break water dan memelihara kedalaman alur pelayaran. Ukuran tempat yang dipasangi groin ini sepanjang break water. Sedangkan untuk revertment juga dibangun sepanjang dermaga. 
Fasilitas Penghubung (Jalan, Drainase, Jembatan, Pagar)

Fasilitas jalan dalam komplek pelabuhan dengan panjang $720 \mathrm{~m}$, drainase terbuka dengan panjang $888,5 \mathrm{~m}$, untuk jembatan 15 $\mathrm{m}^{2}$, serta pagar keliling sepanjang $450 \mathrm{~m}$.

\section{Fasilitas Fungsional}

Fasilitas fungsional merupakan pelengkap fasilitas pokok guna memperlancar pekerjaan/memberikan pelayanan jasa di pelabuhan perikanan serta meningkatkan nilai guna fasilitas pokok diperlihatkan pada Tabel 1 berikut ini.

Tabel 1. Fasilitas Fungsional Pelabuhan Sadeng.

\begin{tabular}{|c|c|c|c|}
\hline No & $\begin{array}{c}\text { Nama } \\
\text { Fasilitas }\end{array}$ & Ukuran & Keterangan \\
\hline 1 & $\begin{array}{l}\text { Gedung } \\
\text { pelelangan } \\
\text { ikan }\end{array}$ & $\begin{array}{c}589 \mathrm{~m}^{2} \\
\text { dan } \\
169 \mathrm{~m}^{2}\end{array}$ & $\begin{array}{l}\text { Gedung } \\
\text { pelelangan } \\
\text { ikan dan } \\
\text { processing } \\
\text { room }\end{array}$ \\
\hline 2 & Pabrik es & $\begin{array}{c}5 \text { ton/ } \\
\text { hari }\end{array}$ & Es curah \\
\hline 3 & Air tawar & $10 \mathrm{~m}^{3}$ & $\begin{array}{l}\text { Kapasitas } \\
\text { tower }\end{array}$ \\
\hline 4 & $\begin{array}{l}\text { Bahan bakar } \\
\text { minyak }\end{array}$ & $\begin{array}{c}16.000 \\
\text { liter }\end{array}$ & $\begin{array}{l}\text { Kapasitas } \\
\text { bunker }\end{array}$ \\
\hline 5 & $\begin{array}{l}\text { Kantor } \\
\text { Administrasi } \\
\text { Pelabuhan }\end{array}$ & $144 \mathrm{~m}^{2}$ & $\begin{array}{l}\text { Administrasi } \\
\text { syahbandar }\end{array}$ \\
\hline 6 & Bengkel & $72 \mathrm{~m}^{2}$ & $\begin{array}{l}\text { Pernbaikan } \\
\text { kapal }\end{array}$ \\
\hline 7 & $\begin{array}{l}\text { Docking } \\
\text { (Slipway dan } \\
\text { railway) }\end{array}$ & 1 unit & $\begin{array}{l}\text { Perbaikkan } \\
\text { kapal }\end{array}$ \\
\hline 8 & $\begin{array}{l}\text { MCK } \\
\text { (mandi, cuci, } \\
\text { kakus) }\end{array}$ & $30 \mathrm{~m}^{2}$ & \\
\hline 9 & $\begin{array}{l}\text { Balai } \\
\text { Pertemuan } \\
\text { Nelayan } \\
\end{array}$ & $144 \mathrm{~m}^{2}$ & \\
\hline 10 & $\begin{array}{l}\text { Tempat } \\
\text { perbaikan } \\
\text { Jaring }\end{array}$ & $96 \mathrm{~m}^{2}$ & \\
\hline 11 & $\begin{array}{l}\text { Pos } \\
\text { Pengawasan } \\
\text { SDI }\end{array}$ & $30 \mathrm{~m}^{2}$ & \\
\hline
\end{tabular}

\begin{tabular}{|c|c|c|c|}
\hline No & $\begin{array}{c}\text { Nama } \\
\text { Fasilitas }\end{array}$ & Ukuran & Keterangan \\
\hline 12 & $\begin{array}{l}\text { Lampu } \\
\text { Navigasi }\end{array}$ & 4 unit & \\
\hline 13 & Rambu Suar & 2 unit & \\
\hline 14 & $\begin{array}{l}\text { Kantor } \\
\text { LANAL }\end{array}$ & $64 \mathrm{~m}^{2}$ & \\
\hline 15 & $\begin{array}{l}\text { Kantor } \\
\text { Dinas } \\
\text { Perhubungan }\end{array}$ & $160 \mathrm{~m}^{2}$ & \\
\hline 16 & $\begin{array}{l}\text { Kantor } \\
\text { Polair }\end{array}$ & $72 \mathrm{~m}^{2}$ & \\
\hline 17 & Areal parkir & $600 \mathrm{~m}^{2}$ & \\
\hline 18 & $\begin{array}{l}\text { Gudang } \\
\text { Peralatan }\end{array}$ & $36 \mathrm{~m}^{2}$ & \\
\hline 19 & $\begin{array}{l}\text { Instalasi } \\
\text { Listrik }\end{array}$ & $\begin{array}{c}25 \\
\text { KVA }\end{array}$ & 2 set \\
\hline
\end{tabular}

Sumber: Kantor Pelabuhan Sadeng

\section{Fasilitas Penunjang}

Fasilitas penunjang memiliki fungsi secara tidak langsung menunjang kelancaran fungsi pelabuhan perikanan meliputi: (1) Mess Operator volume $80 \mathrm{~m}^{2}$, kondisi baik, (2) Rumah Nelayan Andon (13 unit) volume $180 \mathrm{~m}^{2}$, kondisi dan berfungsi dengan baik, (3) Rumah Tamu (2 unit) volume $110 \mathrm{~m}^{2}$, kondisi baik dapat difungsikan, (4) Tempat Ibadah (Masjid) volume $144 \mathrm{~m}^{2}$, kondisi dan berfungsi dengan baik, (5) Pemantau Tsunami 1 unit, kondisi baik, (6) Gapura masuk Pelabuhan 1 unit, kondisi baik/pos jaga

Komparasi fasilitas Pelabuhan Perikanan Pantai (PPP) Sadeng dengan PERMEN No 16 Tahun 2006 tentang Persyaratan Pelabuhan Perikanan.

Untuk Pelabuhan Perikanan Pantai (PPP) Sadeng menurut PERMEN di atas secara umum sudah memiliki fasilitas yang sesuai dengan persyaratkan bahkan beberapa sarana sudah melebihi persyaratan yang meliputi: (1) Mampu melayani kapal perikanan yang melakukan kegiatan perikanan di wilayah Perairan Indonesia. Sudah terpenuhi karena kapal - kapal yang berpangkalan di Pantai Sadeng beroperasi di Samudera India, (2) Memiliki fasilitas tambat labuh untuk kapal perikanan 
berukuran sekurang - kurangnya 10 GT. Sudah terpenuhi jauh melebihi dengan fakta bahwa kapal - kapal sekelas INKA Mina berukuran sekitar 41 GT dapat berlabuh dengan baik, (3) Panjang dermaga sekurang - kurangnya $100 \mathrm{~m}$, dengan kedalaman kolam sekurang - kurangnya $2 \mathrm{~m}$. Sudah memenuhi dan jauh melebihi, kenyataan dermaga di PPP Sadeng mempunyai panjang $485 \mathrm{~m}$ dan kedalaman 5 - $7 \mathrm{~m}$, (4) Mampu menampung kapal perikanan sekurang kurangnya 30 unit atau jumlah keseluruhan sekurang - kurangnya 300 GT.

Daya tamping pada waktu penulis survey sebagai berikut : Menurut persyaratan adalah jumlah kapal yang berlabuh secara bersamaan, sekurang kurangnya 30 unit. Fakta yang ada jumlah kapal yang berlabuh sekitar 68 unit dari jenis perahu motor temple sampai sekelas INKA MINA dengan ukuran 41 GT. Sedangkanjumlah GT nyalebihdari 500 GT, dan (5) Memanfaatkan dan mengelo lalahan sekurang - kurangnya 5 ha, lahan yang ada pada PPP Sadeng sekitar 5 ha. Sedangkan syarat sesuai PER.16/MEN/2006 adalah 5 ha. Jadi fakta syarat luas lahan sudah terpenuhi dan inipun masih dapat dikembangkan kearah utara.

Berdasarkan data yang dikeluarkan dari kantor pelabuhan Sadeng bahwa untuk fasilitas pokok, fungsional dan sarana pendukung memperlihatkan kelayakan untuk berubah tipe dari pelabuhantipe $\mathrm{C}$ kepelabuhan tipe B.

\section{KESIMPULAN}

Hasil analisa bahwa Pelabuhan Perikanan Pantai Sadeng yang merupakan pelabuhan perikanan tipe $\mathrm{C}$ menunjukkan semua fasilitas pelabuhan ini memenuhi persyaratan. Bahkan ada beberapa fasilitas yang melebihi persyaratan teknis berdasar PERMEN No 16 Tahun 2006. Justru fakta yang ada menunjukan kemampuan pelayanan melebihi dari sebuah Pelabuhan Perikanan Pantai tipe $\mathrm{C}$ di semua fasilitas, baik fasilitas pokok, fasilitas fungsional maupun fasilitas penunjang. Hanya beberapa fasilitas fungsioal yang tersedia kurang optimal sebagai contoh pemanfaatan dock/bengkel dikarenakan pengguna dan pengelola kurang bersinergi.

Dari sisi operasional PPP Sadeng masih mampu melayani semua aktivitas yang ada walaupun terjadi peningkatan jumlah dan ukuran kapal ikan.

\section{DAFTAR PUSTAKA}

Arsyad, M., 2014, Analisis Tingkat Pemanfaatan Fasilitas Pangkalan Pendaratan Ikan Bonehalang, Skripsi. UNHAS, Makassar.

Pelabuhan Perikanan Wahana Penyaluran Investasi Usaha Departemen Pertanian, 1994.

Peraturan Menteri Kelautan dan Perikanan PER.16/MEN/2006 Tentang Kepelabuhan Perikanan. Kementrian Kelautan dan Perikanan Indonesia, 2006.

Surat Keputusan Menteri Kelautan dan Perikanan No.: Kep.10/MEN/2004, Tentang Pelabuhan Perikanan Jakarta , Departemen Kelautan dan Perikanan Dinas Kelautan dan Perikanan Propinsi Daerah Istimewa Yogyakarta, 2004.

Peraturan Menteri Kelautan dan Perikanan Nomor 8/MEN/2012, Tentang Kepelabuhan Perikanan, 2012.

Suryana, E., 2008, Analisis sistem pengelolaan pelabuhan perikanan Pantai Labuan Provinsi Banten, Tesis, UT, Jakarta.

Yuspardianto., 2006, Studi Fasilitas Pelabuhan Perikanan Dalam Rangka Pengembangan Pelabuhan Perikanan Samudera Bungus Sumatera Barat. Mangrove Dan Pesisir. 